\title{
Influence of the World Wide Web on the citation patterns of Master of Information Studies students at the University of Natal during the period 1996 to 2002
}

\author{
Patrick Ngulube ${ }^{\prime}$ \\ University of South Africa, Department of Information Science, University of South Africa \\ ngulup@unisa.ac.za \\ Elizabeth Conceição Garçia Thompson ${ }^{2}$ \\ Information Studies Programme, School of Sociology and Social Studies \\ University of KwaZulu-Natal, South Africa \\ ethompson@yahoo.com or ecgthompson@mweb.co.za
}

Received: $10^{\text {th }}$ March 2008

Accepted: $5^{\text {th }}$ October 2008

\begin{abstract}
The Web has significantly changed the milieu of research and study. The study determined how this changing research and study environment has influenced the research behaviour of master's students at the University of Natal ${ }^{3}$ in South Africa. Explicit examples of the effect of the Web were drawn from analysing changes in the citation patterns of masters' theses during the years 1996, 1999 and 2002. Tacit influences on students' citation behaviour were inferred from an investigation of the level and nature of research supervisors' use and support of the Web for research. Findings of this study concluded that the use of the Web by students was rather limited. The use of this medium was disparate, with a few bibliographies accounting for much of the growth of Web resources. The study revealed greater support for this medium from the masters' programme supervisors than was evidenced from a citation analysis of the bibliographies of theses.
\end{abstract}

Keywords: Bibliographies, bibliometrics, citation analysis, information seeking, internet, world wide web

\section{Context and description of the problem}

The importance of the World Wide Web (WWW) as rich information resource and research tool is widely recognised (Adogbeji and Akporhonor 2005; Al-Ansari 2006; Anasi 2006; Islam and Panda 2007; Jepsen et al., 2004; Kaniki 1999; Ngai et al., 2008; Spennemann 2007). Described as accommodating both traditional and new information spaces (Fourie 2002: 53), the Web has significantly changed the milieu of research and study.

The Web has heralded powerful finding aids such as subject directories, subject guides, subject gateways, vortals, portals, home pages and search engines. It has contributed significantly to informal scholarly communication, through the availability of discussion lists and forums, the growth of electronic pre-prints databases and other previously difficult to locate grey sources. Acknowledging this new research environment is the growing body of literature, surveying Internet use amongst different information seeking groups in academic environments (Al-Ansari 2006; Middleton 2005; Mugwisi and Ocholla 2002; Olalude 2007; Spennemann 2007) and studies that confirm the impact of the Internet on scholarly communication (Thelwall 2002).

In spite of this, the Web has serious disadvantages as a research tool and these are well documented in the literature (Wachbroit 200I). Researching on the Web requires some level of network literacy that has been described as (Savolainen 2002: 223-4):

- Knowledge of information resources available on the Internet;

- Skilful use of ICT tools to access networked sources;

- Judgement of the relevance of information; and

- Use of computer-mediated communication tools.

Intrinsic to the very nature of the Web is its lack of organisation. There is no universal catalogue to identify and retrieve a particular piece of information, and the best search engines only capture a portion of the Web (Baeza-Yates and RebeiroNeto 2000). The Web is a self-publishing medium and the usual checks, specifically peer review, that exist between the

I. Patrick Ngulube (PhD), is a professor of Information Science at the University of South Africa, Department of Information Science, Pretoria

2. Elizabeth Conceição Garçia Thompson, who obtained her master's degree in Information Studies at the University of Natal is a librarian in Dubai

3. The University of Natal in South Africa became the University of KwaZulu-Natal in 2004 as result of merging with the University of Durban-Westville 
writer and the reader may be missing. Moreover, and of concern to scholarly communication, the Web at times lacks stability and continuity with sites changing, moving or disappearing altogether (Parker 2007; Wachbroit 200I).

Of interest to the study was how this changing research and study environment has affected the research behaviour of students in a higher education environment in Africa, specifically at the research-entry level of master's degree programmes. A point of reference was bibliometric studies conducted in post-industrial countries that measured changes in students' information seeking behaviour with the advent of, and access to the Web (Davis 2003; Grimes and Boening 200I; Jenkins 2002; Oppenheim and Smith 200I; Williams and Fletcher 2006).

Findings of these studies indicate changing patterns in the level of use of different types of information sources and an increase in the use of online resources. An accompanying concern expressed by teaching staff and librarians, and explored by these studies, was that of the research quality of the work resulting from the use of the Web and the students' indiscriminate use of non-scholarly resources. A significant observation in these and other related studies (Davis 2003; Jenkins 2002; Rowley 2002; Urquhart 2003) was that students' information behaviour was largely determined by teaching faculty's expressed expectations and interventions.

While these studies have focused on undergraduate information behaviour in post-industrial tertiary environments, they nevertheless provide a useful vehicle to measure the impact of the WWW on the information and research behaviour of research-entry students in Africa's higher education environments. The African context provides an interesting backdrop to this investigation, specifically in the light of a perceived importance of the Internet for research and study (Ehikhamenor 2003; Kaniki 1999; Mugwisi and Ocholla 2002) and given the limited physical collections and limited access to the Internet (Ani, Esin and Edem 2005; Odero-Musakali and Mutula 2007; Rosenberg 200I; Sturges and Neill 1998).

Empirical studies investigating Internet use in academic environments in Africa, including the research conducted by Anasi (2006), Ehikhamenor (2003), Kaniki (1999), Mugwisi and Ocholla (2002) Omotayo (2006) and Shezi (2006) remain largely at a survey level, identifying perceptions rather than determining actual use. Factors that affect students' use of electronic information sources including the WWW have also been explored at a conceptual level. Of note are the prescriptive theories of information seeking and retrieval behaviour employing cognitive paradigm approaches (Cosijn 2000; Ingwersen 2000; Jepsen et al., 2004; Nel 200I; Thompson and Cronje 200I).

While there is evidence of African scholars and their institutions adopting, either through individual initiatives or through regional and international support, information and communication technologies (Odero-Musakali and Mutula 2007; Mugwisi and Ocholla 2002: 145) and of academic libraries championing this movement (Rosenberg 200I: 15), and moreover, supporting the assimilation of Web sources in acquisitions policies (Geslin 2002), it is apparent that greater quantitative research data determining how students are performing in this new research environment is required (Mugwisi and Ocholla 2002: 144).

The current study examined both explicit examples of the effect of the Web on students' citation behaviour and tacit influences that may determine the extent of that effect. Explicit examples of the effect of the Web were drawn from measuring and evaluating changes in citation patterns of MIS theses during 1996 to 2002. Tacit influences were inferred from an investigation of the level and nature of MIS supervisors' use and support of the Web for research and of a background study of the facilities, resources and services supporting student access to the Web during the period under investigation. The study was guided by the following five research questions:

- How has the level and range of use of traditional print formats changed during the period under study?

- Do cited Uniform Resource Locators (URLs) point to the correct document?

- What proportion of students' online citations may be categorised as non-scholarly?

- What are the expectations and preferences of MIS supervisors in regards to the use of the Web by their master's degree students for research?

- What changes have MIS supervisors perceived in the citation behaviour of students under their supervision?

\subsection{Access to web resources}

Central to an investigation of the effect of the Web on students' citation behaviour is obviously the issue of access. Common barriers affecting the level of access, reported in surveys investigating Internet use in African academic environments (Ehikhamenor 2003; Mgobozi and Ocholla 2002; Ocholla 1999; Odero-Musakali and Mutula 2007), include limited physical access, slow connection speeds and poor information and computer literacy skills. Other barriers or enablers that may specifically determine the nature of access, include the availability and promotion of information resources, the responsibilities and interventions of supervisors and the nature and expectations of academic programmes (Ocholla 1999; Davis 2003; Urquhart 2003; Rowley 2002).

Davis (2003: 4I) attributed the change in students' citation behaviour to the wiring or connecting of the North American college campuses. Fledging access to the Web was initially introduced to the University of Natal by the SA Jnl Libs \& Info Sci 2008, 74(2) 
Information Technology Division (ITD) in 1996 and four terminals were available for student use on the Pietermaritzburg Campus (Naidoo 2003). In 1999 facilities were upgraded and the number of terminals was increased and by the end of 2002 a total of 358 personal computers were available and were accessible in the various personal computer laboratories scattered throughout the Campus (Naidoo 2003). Two of these laboratories were reserved exclusively for the use of postgraduate students. Most of the computer laboratories were open 24 hours a day and were all equipped with printing facilities (University of Natal 2003).

Additionally, limited, access to the WWW was being provided by the University of Natal Library, Pietermaritzburg (UNLP). The Main Library availed four computers for searching online databases that the Library subscribed to. The other two faculty-based libraries at Life Sciences and Law provided a further two workstations each for access to Web resources. It is clear from the foregoing that resource constraints and systemic barriers were not likely to adversely affect the ability of MIS students to access and use the Web resources.

A necessary extension of traditional collection development activities undertaken by an academic library is the development of easy to use, comprehensive and current "Web bibliographies" that provide users with a gateway or portal to appropriate and authoritative information resources (Herring 200I). At the time of the period under investigation, the Library's website included e-books and e-journals, both free or subscription based; e-newspapers; online indexes and abstracts and full-text services, either paid for or available for limited periods through free trials; and subject links to other relevant gateways or portals (Kuhn 2003).

UNLP also provided user education programmes aimed at making "all students self sufficient in appropriate bibliographic and information retrieval skills dependent on level of study [and] bearing in mind the lifelong learning component of a tertiary education" (University of Natal Library, Pietermaritzburg 2000). The education programmes included library orientation tours, instruction on the use of the computerised catalogue, subject-specific library instruction courses and instruction and demonstration of various electronic and online databases. Network literacy or more specifically, instruction on the use of Web resources covered all online databases that the Library subscribed to. However, the reported numbers of students attending these various education programmes continued to be low (Aitchison 2003).

1.2 Master of Information Studies Programme: University of Natal

Research at the University of Natal was conducted either through the production of a major thesis or completion of a series of courses at master's degree level and the production of a minor or limited length thesis (Ngulube 2005). Both masters' programmes required students to design and conduct independent research with the support of nominated supervisors. According to Kaniki (2000: 39), a pre-requisite for the training and development of competent researchers is a team of equally competent supervisors who are objective and consistent in their guidance and assessment.

Accordingly supervisors are required to guide masters' candidates in the selection and location of relevant literature and other resources, including researchers working in related fields. Furthermore, and of interest, supervisors are responsible for imparting the conventions of scholarship to candidates in the drafting of their theses (Kaniki 2000; Ngulube 2005).

\section{Methodology}

Citation and reference analyses have been extensively used to establish the structure of scholarly activities in many disciplines (Garfield 1979; Jaffe 1997: 9; Smith 198I: 95). Davis (2003), Grimes and Boening (200I), Jenkins (2002), Oppenheim and Smith (200I) and Williams and Fletcher (2006) used citation analysis to establish the effect the WWW on the citation patterns of students. Oppenheim and Smith (200I) analysed the citations of 60 final-year undergraduate assignments submitted in the years 1997, 1998 and 2000. Davis (2003) studied students' citation practices in the years 1996, 1999, 2000 and 200I. Jenkins (2002) analysed a total of 854 citations from II6 student undergraduate papers. Finally, Williams and Fletcher (2006) used 250 engineering master's theses accepted between 2000 and 2004 to determine the materials used by graduate students in their research.

Citation analysis was deemed to be suited to measure and compare the level of use of different types of formats, and the manifest attributes of online citations of MIS theses submitted by the students at the University of Natal during the period under study. The study adopted a normative approach to an evaluation of students' citation behaviour and limited its investigation to the following:

- Background study of the facilities and resources on the UNP campus that supported access during this period;

- The time-frame 1996 to 2002 , in which access to Web facilities and resources was first introduced and developed at the University of Natal; and

- A survey of MIS supervisors' support of the WWW for research.

SA JnI Libs \& Info Sci 2008, 74(2) 
Although a total of 46 theses were identified the study focused on the list of references of $24(52 \%)$ theses that were purposively selected. Middleton (2005) also used a purposive sample to study means of how the quality of student bibliographies can be measured. Altogether a total of 2096 bibliographic citations were analysed, that is, 579 for 1996, 836 for 1999 and 68I for 2002. In another related study, Sam and Tackie (2007) used 2212 citations to established the kind of information resources used by master's students.

The current study used a purposive sample based on the assumption that theses at the beginning, middle and end of the time frame had a possibility of reflecting changes in citation patterns. The assumption was based on the fact that the background study of the problem under investigation revealed that student access to Web resources on campus was first introduced in 1996, the quality and level of access to the Web was significantly improved in 1999 (Naidoo 2003), and the year 2002 had the potential to best reflect the influence of the Web on citation behaviour as that was when the University's Internet connection was improved, the Library's Web portal upgraded and the use of certain databases became significantly high and popular (Hoskins 2003).

On the other hand, the survey method was employed by the current study to help describe MIS supervisors' support of the Web for research. A common observation in the literature is that of teachers' role in determining students' information gathering behaviour (Davis 2003; Grimes and Boening 2001; Rowley 2002; Schwartz 2002; Urquhart 2003).

The survey method with a validated self-administered questionnaire was used for collecting data as it was the case with Al-Ansari (2006) when investigating patterns of Internet use by faculty including Internet resources that they used. The population of the study consisted of the Head of the Information Studies Programme, two senior lecturers and two lecturers and it was representative of the staff responsible for the MIS programme between 1996 and $2002^{4}$.

\section{Research findings and discussions}

This section presents and discusses the major findings of the study. Firstly, the analysis of the list of references of the theses is presented. The results of the a survey of the MIS supervisors who were responsible for the master's degree level output for the period of the study conclude this section.

\subsection{Changes in the level and range of use of traditional formats}

To determine changes in the level and range of use of different types of formats, citations of MIS list of references for the years 1996, 1999 and 2002 were coded according to the following categories:

- Formal formats - encyclopaedias, handbooks, manuals, directories, dictionaries, books, chapters in books and journals;

- Informal formats - unpublished theses and dissertations, conference and seminar papers and proceedings, reports and other ephemeral or grey literature.

- Other formats:

$\infty$ Grey literature - government and organisation documents (it is notable that grey literature has become far more widely available and accessible in an electronic environment than it was in a traditional print environment (Halliday 200I);

$\infty$ Non-scholarly - newspapers and magazines;

$\infty$ Miscellaneous print sources, including course and lecture notes and student papers;

$\infty$ Personal communications; and

$\infty$ Non-traditional formats - online citations such as Web pages and discussion forums.

The above categories were largely based on Davis and Cohen and Hinchliffe et al., (2003) .

Firstly, the list of references of the six theses submitted in 1996 was analysed. A total of 579 citations were coded, counted and categorised (see Table I). Formal formats accounted for $77.4 \%$ of the total size of the list of references. Informal formats accounted for $6.7 \%$ of all citations. Web-based formats were not found in any of the theses.

4. The fifth member of the population was later withdrawn from the analysis due to a self-expressed limited involvement in the supervision of MIS theses for the period under study. 
Table I Occurrence of formats in the list of references of theses, 1996

\begin{tabular}{|c|c|c|c|c|c|c|c|c|}
\hline \multirow[t]{2}{*}{ Format } & \multicolumn{8}{|c|}{ Thesis case number $(n=6)$} \\
\hline & 1 & 2 & 3 & 4 & 5 & 6 & Score & $\%$ \\
\hline Books & $40.3 \%$ & $59.2 \%$ & $48.8 \%$ & $35.8 \%$ & $47.6 \%$ & $37.1 \%$ & 256 & 44.2 \\
\hline Journals & $41.4 \%$ & $11.3 \%$ & $20.9 \%$ & $58.2 \%$ & $18.4 \%$ & $48.6 \%$ & 192 & 33.2 \\
\hline Theses \& Dissertations & $2.2 \%$ & $1.4 \%$ & $7.0 \%$ & $1.5 \%$ & $4.1 \%$ & $7.1 \%$ & 20 & 3.5 \\
\hline Conference Papers \& Proceedings & $2.8 \%$ & $7.0 \%$ & $2.3 \%$ & - & $2.7 \%$ & $2.9 \%$ & 17 & 2.9 \\
\hline Research \& Technical Reports & $1.1 \%$ & - & - & - & - & - & 2 & 0.3 \\
\hline Newspapers \& Magazines & $2.2 \%$ & $-\%$ & - & - & $2.0 \%$ & - & 7 & 1.2 \\
\hline Organisation Documents & - & $7.0 \%$ & $4.7 \%$ & $4.5 \%$ & $12.2 \%$ & $-\%$ & 28 & 4.8 \\
\hline Government Documents & $2.8 \%$ & - & $7.0 \%$ & - & - & $2.9 \%$ & 10 & 1.7 \\
\hline Miscellaneous & $1.7 \%$ & - & $4.7 \%$ & - & $2.0 \%$ & $1.4 \%$ & 9 & 1.6 \\
\hline Personal Communications & $5.5 \%$ & $14.1 \%$ & $4.7 \%$ & - & $10.9 \%$ & - & 38 & 6.6 \\
\hline Web-based Documents & - & - & - & $-\%$ & - & - & - & - \\
\hline Size of the list of references & $100 \%$ & $100 \%$ & $100 \%$ & $100 \%$ & $100 \%$ & $100 \%$ & 579 & 100 \\
\hline
\end{tabular}

Next, the nine MIS theses that were submitted in 1999 and their list of references were analysed. A total of 836 citations were coded, counted and categorised (see Table 2). Formal formats of scholarly communication continued to predominate in 1999 and accounted for $70 \%$ of the total size of the list of references. Informal formats accounted for $6.7 \%$ of all citations. Web-based documents accounted for $1 \%$ of all citations, but their use was limited to two theses.

Table 2 Occurrence of formats in the list of references of theses, 1999

\begin{tabular}{|c|c|c|c|c|c|c|c|c|c|c|c|}
\hline \multirow[t]{2}{*}{ Format } & \multicolumn{11}{|c|}{ Thesis case number $(n=9)$} \\
\hline & 1 & 2 & 3 & 4 & 5 & 6 & 7 & 8 & 9 & Total & $\%$ \\
\hline Books & $19.0 \%$ & $28.6 \%$ & $25.0 \%$ & $33.0 \%$ & $53.9 \%$ & $44.7 \%$ & $37.0 \%$ & $32.5 \%$ & $47.0 \%$ & 288 & 34.4 \\
\hline Journals & $10.3 \%$ & $57.1 \%$ & $17.3 \%$ & $43.3 \%$ & $30.3 \%$ & $25.5 \%$ & $50.0 \%$ & $54.0 \%$ & $27.3 \%$ & 300 & 35.9 \\
\hline Theses \& Dissertations & - & $3.9 \%$ & $2.4 \%$ & $7.2 \%$ & $3.4 \%$ & $6.4 \%$ & $9.3 \%$ & $4.0 \%$ & $6.1 \%$ & 39 & 4.7 \\
\hline Conference Papers \& Proceedings & $17.2 \%$ & $1.3 \%$ & $0.6 \%$ & $2.1 \%$ & - & - & $0.9 \%$ & $1.6 \%$ & - & 17 & 2.0 \\
\hline Research \& Technical Reports & - & - & - & - & - & - & - & - & - & - & - \\
\hline Newspapers \& Magazines & - & - & $1.8 \%$ & $11.3 \%$ & $6.7 \%$ & - & - & $1.6 \%$ & $7.6 \%$ & 27 & 3.2 \\
\hline Organisation Documents & $22.4 \%$ & $5.2 \%$ & $22.0 \%$ & $1.0 \%$ & $1.1 \%$ & $10.6 \%$ & $0.9 \%$ & $2.4 \%$ & $6.1 \%$ & 69 & 8.3 \\
\hline Government Documents & $12.1 \%$ & $2.6 \%$ & $7.1 \%$ & $1.0 \%$ & $2.2 \%$ & $4.3 \%$ & - & $1.6 \%$ & $6.1 \%$ & 32 & 3.8 \\
\hline Miscellaneous & $1.7 \%$ & $1.3 \%$ & - & - & - & - & $1.9 \%$ & - & - & 4 & 0.5 \\
\hline Personal Communications & $5.2 \%$ & - & $23.8 \%$ & $1.0 \%$ & $1.1 \%$ & $8.5 \%$ & - & $2.4 \%$ & - & 52 & 6.2 \\
\hline Web-based Documents & $12.1 \%$ & - & - & - & $1.1 \%$ & - & - & - & - & 8 & 1.0 \\
\hline Size of the list of references & $100 \%$ & $100 \%$ & $100 \%$ & $100 \%$ & $100 \%$ & $100 \%$ & $100 \%$ & $100 \%$ & $100 \%$ & 836 & 100 \\
\hline
\end{tabular}

Finally, the list of references of the nine MIS theses submitted in 2002 were also analysed and a total of 68 I citations were coded, counted and categorised (see Table 3). Formal formats accounted for $70 \%$ of all citations. Informal formats accounted for an average of $11 \%$ of all citations and this increase reflected an increase in the use of conference papers and research reports. Web based documents accounted for $7 \%$ of all citations.

Table 3 Occurrence of formats in the list of references of theses, 2002

\begin{tabular}{llllllllllll}
\hline \multicolumn{1}{c}{ Format } & \multicolumn{10}{c}{ Thesis case number (n=9) } \\
\hline & $\mathrm{I}$ & 2 & 3 & 4 & 5 & 6 & 7 & 8 & 9 & Score & $\%$ \\
Books & $43.2 \%$ & $29.9 \%$ & $38.2 \%$ & $29.4 \%$ & $27.5 \%$ & $67.7 \%$ & $27.7 \%$ & $57.4 \%$ & $35.8 \%$ & 262 & 38.5 \\
Journals & $21.6 \%$ & $36.4 \%$ & $38.2 \%$ & $47.1 \%$ & $36.3 \%$ & $7.7 \%$ & $34.9 \%$ & $13.1 \%$ & $37.3 \%$ & 214 & 31.4 \\
Theses \& Dissertations & $1.4 \%$ & $7.8 \%$ & - & $5.9 \%$ & $8.8 \%$ & - & $4.8 \%$ & $6.6 \%$ & $4.5 \%$ & 30 & 4.4 \\
Conference Papers \& Proceedings & $2.7 \%$ & $3.9 \%$ & - & $1.2 \%$ & $2.5 \%$ & $6.2 \%$ & $9.6 \%$ & $9.8 \%$ & $4.5 \%$ & 29 & 4.3 \\
Research \& Technical Reports & - & $5.2 \%$ & $2.2 \%$ & $1.2 \%$ & $3.8 \%$ & - & $3.6 \%$ & $4.9 \%$ & - & 16 & 2.3 \\
Newspapers \& Magazines & - & - & $1.1 \%$ & - & $1.3 \%$ & $1.5 \%$ & $1.2 \%$ & $6.6 \%$ & - & 8 & 1.2 \\
Organisation Documents & $2.7 \%$ & $3.9 \%$ & $1.1 \%$ & $4.7 \%$ & $8.8 \%$ & $1.5 \%$ & $7.2 \%$ & - & $3.0 \%$ & 26 & 3.8 \\
Government Documents & $10.8 \%$ & $3.9 \%$ & $10.1 \%$ & $2.4 \%$ & - & - & $1.2 \%$ & - & $1.5 \%$ & 24 & 3.5 \\
Miscellaneous & $1.4 \%$ & $1.3 \%$ & - & - & - & - & $1.2 \%$ & $1.6 \%$ & - & 4 & 0.6 \\
Personal Communications & & $2.6 \%$ & $9.0 \%$ & $5.9 \%$ & $3.8 \%$ & - & - & $-\%$ & $3.0 \%$ & 20 & 2.9 \\
Web-based Documents & $16.2 \%$ & $5.2 \%$ & - & $2.4 \%$ & $7.5 \%$ & $15.4 \%$ & $8.4 \%$ & - & $10.4 \%$ & 48 & 7.0 \\
Size of the list of references & $100 \%$ & $100 \%$ & $100 \%$ & $100 \%$ & $100 \%$ & $100 \%$ & $100 \%$ & $100 \%$ & $100 \%$ & 681 & 100 \\
\hline
\end{tabular}


Figure I gives an overview of the occurrences of different type of formats used in the theses under investigation.

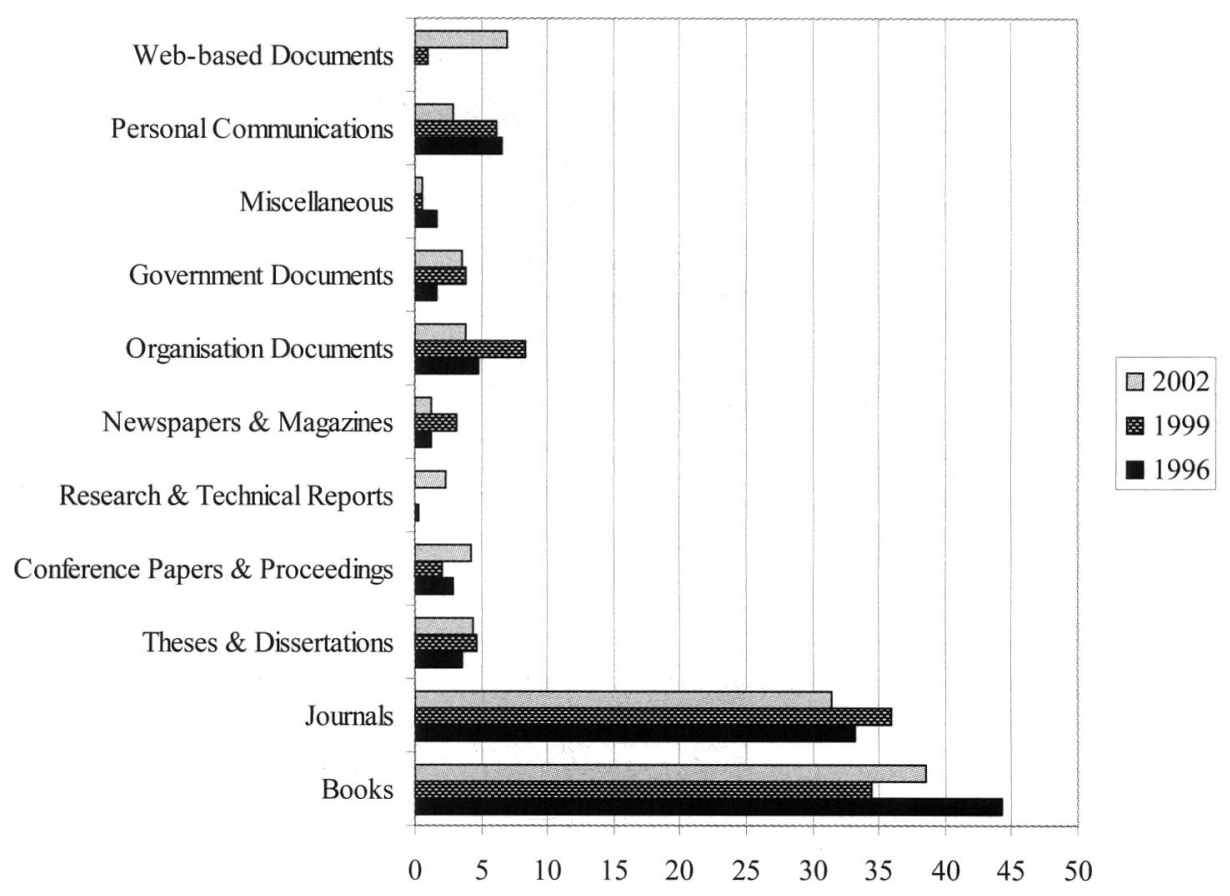

Figure 1 Occurrences of different type of formats in the theses (expressed as a \%)

It is evident from Figure I that there was a drop in the use of the book format from 1996 to 2002 by $5.7 \%$. The occurrence of the journal format at group level remained relatively consistent. Individual use of journals however was disparate with a difference of $47 \%$ and $43 \%$ respectively between the least and highest incidence for this format in 1996 and 1999 (see Table I and 2). In 2002 the difference in the least and highest occurrence of the journal format at an individual level dropped to $39 \%$ (see Table 3). At an individual level the highest occurrence of the journal format dropped from $58 \%$ in 1996 to $57 \%$ in 1999 and witnessed a further 10\% drop to $47 \%$ in 2002 (see Table I, 2 and 3). The use of unpublished conference papers and research reports increased in the last year of the study.

The incidence of Web-based documents rose by $6 \%$ from 1999 to 2002 . With few exceptions, other formats remained relatively stable with peaks and dips more reflective of individual practices than group behaviour. This is particularly the case with the increase in use of organisation documents and personal communication in 1999 (see Table 2). Although the Web has increased access to a variety of information resources (Herring 2002; Davis 2003; Halliday 200 I; Odlyzko 200I), it is evident from Figure I that the masters students did not extensively utilize Web-based sources.

The citation behaviour of the MIS students during the period under study was consistent with the conclusions of Mgobozi and Ocholla (2002) and Smith and Oppenheim (200I). Smith and Oppenheim (200I) observed a continued dependence on monographs in assignments for the year 2000 when $40 \%$ of all citations were to book formats. The same trend was established by studies such as those of Sam and Tackie (2007) in Ghana and Zhang (2007) in the United States. Journal use for 2000 was only $29.5 \%$ of all citations. On the other hand, Mgobozi and Ocholla (2002) noted the low use of electronic journals by academics, librarians and postgraduates of the universities of Natal and Zululand. The findings were different to the studies by Friedlander (2002), Islam and Panda (2007), and Tenopir and Ennis (2002) which established a preference for consulting Internet resources by researchers as opposed to printed sources in answering reference queries. Oppenheim and Smith (2001: 303) indicated a growing reliance on the use of the Internet from $1.9 \%$ in 1997 to $17.2 \%$ in 1999.

An obvious change in citation behaviour was the drop in the occurrence of formal formats by $7.5 \%$ from 1996 to 2002. Despite the drop, formal formats continued to predominate and on average comprised two-thirds of the list of references. An obvious increase from 1999 to 2002 was in the use of informal formats. This can be largely attributed to the increased use of research reports and conference proceedings since 1999.

The occurrence of Web-based formats was also limited to an individual level. The low occurrence of Web formats in research outputs in an African environment was observed by Olalude (2007) in a study on the extent to which librarians and other information professionals in sub-Saharan Africa utilized Internet resources in their scholarly publications between 2000 and 2005. 


\subsection{Stability of Uniform Resource Locators}

A pre-requisite of a scholarly publication is that it should be reliably accessible and retrievable over time (Halliday 200I). The issue of the continued accessibility of electronic sources affects the formats' "acceptability among scholars as a legitimate medium of formal scholarly communication" (Zhang 1998: 249). Davis (2003: 50) concurred and ascertained that "a viable link - whether in print or electronic form - is absolutely necessary in order to preserve scholarly communication". In a nutshell, "link rot" or the decay of a URL renders electronic citations inaccessible and in turn undermines the foundations of scholarly research (Parker 2007). The American Psychological Association (2003) further emphasised the importance of the stability of URLs by stating that:

The URL is the most critical element: If it doesn't work, readers won't be able to find the critical material, and the credibility of your paper or argument will suffer. The most common reason URLs fail is that they are transcribed or typed incorrectly; the second most common reason is that the document they point to has been moved or deleted.

Of the total online citations tested, $39(70 \%)$ URLs continued to point to the correct document approximately five years after first being cited. Documents that could not be located from the URLs provided by online citations underwent two levels of investigation. Firstly the relevant parts of the URLs were visited to see whether documents had been moved within the sites and if not successful, a second step was to search for document titles or authors through a search engine, using phrase and open search statements. The Google and Yahoo search engines were used for that purpose and only the first page of hits was used to locate a document. The strategy for verifying the accuracy and persistence of URLs was used by Davis and Cohen (200I). In this manner a further nine (16\%) documents were found. Some of the URLs might have been inaccessible because they may have been typed incorrectly as pointed out by the American Psychological Association (2003) and Davis and Cohen (200I).

In their study, Harter and Kim (1996) found that online citations were frequently inaccessible and that overall, only half were located. Grimes and Boening (200I) established that $30 \%$ of URLs cited by students and verified by the researchers within three weeks of use, were no longer available. Of the 56 online citations tested from the theses, 17 (30\%) of the URLs did not point to the correct document. More than half of the online citations were thus accessible. Davis (2003) reported an improvement in the persistency of URLs from 1996 to $200 \mathrm{I}$ and attributed this improvement to students being more selective and choosing sites with stable identifiers. Herring (2002) also found a better level of persistence as only $18 \%$ of online citations could not be found at the indicated URLs.

3.3 The scholarly attributes of online citations

Scholarly sources available in a traditional print academic environment progress through channels of validation and verification by editors, publishers and faculty-librarian collaboration before being utilised by students. The Web environment does not afford these gatekeepers the same privilege. Consequently, sources available on the Web may not necessarily meet the standards previously required from a traditional formal scholarly publication (Grimes and Boening 200 I; Leckie 1996). In that regard, the manifest content of a total of 56 online citations for the years 1999 and 2002 (see Table 2 and 3) were analysed to determine the following attributes:

- Evidence of scholarly activity through the provision of references;

- Evidence or statements of peer review;

- Evidence of academic or research affiliation;

- Format type; and

- Domain type.

Of the 48 online citations that could be accessed the following manifest attributes were observed.

- Sixteen (36\%) provided bibliographic references.

- Twenty-six (54\%) indicated an academic affiliation to a higher education or a research institution.

- Five $(10 \%)$ showed that they had been refereed.

- Five (10\%) demonstrated evidence of peer review, academic or research affiliation and bibliographic references.

- Five (10\%) showed evidence of both academic and research affiliation and bibliographic references.

- Five (10\%) demonstrated evidence of only bibliographic references.

- Fifteen (31\%) exhibited only the attribute of an academic or research affiliation.

- Eighteen (39\%) did not demonstrate any manifest scholarly attributes.

- The education (.edu) and academic (.ac) generic domains names accounted for $48 \%$ of all domains cited.

- Citations with an organisation (.org) domain name accounted for $34 \%$ of all online documents.

- Government (.gov) domain names were encountered $10 \%$ of the time and included acts, white papers, manuals and other miscellaneous documents.

- The domain name for sites hosted by commercial interests (.com) was least observed in online citations. 
These findings suggest that MIS students' citation behaviour in this regard, is more consistent with Grimes and Boening's (200I) study of undergraduates' use of Web resources, and less consistent with Herring's (2002) study of scholars' use of electronic resources. Grimes and Boening (200I: 20) found that undergraduates were largely using unauthenticated Web documents and cited everything from "junior high school Web sites to publicity sites". The use of non-scholarly Web resources may be attributed to lack of clear instructions or guidelines in the use of information resources from course instructors (Davis 2003; Grimes and Boening 200I; Herring 200I). A comparative analysis of student citations from different disciplines at a North American college (Jenkins 2002) found that instructors' requirements effected student's citation behaviour significantly, specifically in terms of the use of Web resources.

\subsection{Survey of Master of Information Studies supervisors}

The study also explored a possible relationship between the extent of the Web's effect on student citation behaviour and MIS supervisors' own preferences, expectations and promotion of the Web for student research and their opinions on the effect of the Web on student research quality. The nature of the survey was preliminary and exploratory and the intention was to juxtapose group level information behaviour of MIS supervisors with that of MIS students' citation behaviour. The survey data should be treated with some caution. The sample that was studied was quite small.

\subsubsection{Expectations and preferences for students' information gathering behaviour}

The survey revealed that:

- The majority of MIS supervisors supported an equally balanced and frequent use of both a print and online medium for identifying and locating relevant information sources by their students.

- The majority of supervisors preferred that students use an online environment first for identifying relevant information sources.

- The predominant format all MIS supervisors expected students to use most of the time for their research, and that they referred students to most of the time was the journal format, in both a print and online medium.

The study revealed a greater support by MIS supervisors for the use of the Web environment than was evident from a citation analysis of MIS list of references. On the most part, MIS supervisors expected their masters' students to exhibit similar information gathering behaviour as they did. That was consistent with findings of related studies (Friedlander 2002; Herring 200I) that reported academics' preference for a hybrid print and electronic research environment. However, Islam and Panda (2007: 760) found that $70 \%$ of the respondents preferred print materials more. These findings were in resonance with those of the current study. There was no balance between the use of Internet and print information resources (see Figure I). Although faculty operated on "an expert mode" in terms of information gathering behaviour and expect the same behaviour from their students, especially at postgraduate level (Leckie 1996), that is not always the case as the results of an analysis of students' citations revealed.

\subsubsection{Views of the supervisor on the influence of the Web}

The last part of the questionnaire sought to establish supervisors' views on the influence of the Web may have had on students' research behaviour. The majority of MIS supervisors were of the opinion that research entry students in African higher education environments have the necessary competencies to evaluate non-scholarly resources available online and cited in their bibliographies. This opinion is not wholly consistent with the findings of a content analysis of online documents cited in bibliographies of MIS theses submitted in 2002. Only 10\% of the sample of online citations analysed exhibited the traditional attributes of a scholarly source.

MIS supervisors provided opinions on both the utility of the Web for research and secondly on the effect of the Web on the quality of students research. Respondents indicated both strong and more judicious support for the utility of the Web in research. The findings were supported by Islam and Panda (2007) who revealed that $97 \%$ of the respondents considered the Internet as important to their research work.

A tentative correlation found by the current study was that supervisors who supported the Web more strongly (in terms of the amount and frequency in the use, expected use and promotion of Web medium resources) and who went on to express the Web's importance in an environment with limited print resources and for particular subject areas, perceived greater change in their students' citation behaviour. This finding is consistent with related studies that observed that teaching faculty's own information behaviour, expectations and interventions strongly determine student citation behaviour (Davis 2003; Grimes and Boening 2001). However, what should be borne in mind is the fact that the size of the population that was studied was small and the analysis preliminary. Thus, greater research is required to continue to test this correlation.

\section{Conclusions and recommendations}

The study found that the level of influence of the Web on students' citation behaviour was limited and disparate with a small number of bibliographies accounting for most of the changes. The range of traditional print informal formats grew 
to include more unpublished research reports and the use of the book format slightly dropped but continued to predominate.

With very few exceptions, MIS students continued to be dependant on a hardcopy print environment and continued to favour the book format. Although, MIS supervisors supported the use of the Web for their research and their students' research needs, an analysis of students' citations demonstrates that they were not effectively communicating their expectations of the use of the medium adequately. The supporting infrastructure provided by the University was adequate, but the limited use of Web resources might have been caused by other factors such as limited promotion or marketing of the resource and lack of network literacy among the students whose theses were analysed.

A greater intervention from teaching faculty, in this case, supervisors, in the support of the appropriate student research behaviour is recommended. The extent of supervisors' expectations in the use of formats and mediums should be clearly communicated and followed-up. As observed by Leckie (1996) and Grimes and Boening (200I) teaching faculty staff should not pre-suppose that students have the same skills or are capable of the same expert researcher model as they are. Given the disparate use of the Web medium, MIS students are in need of greater intervention from their supervisors in adopting and adapting to new and hybrid research environments.

The gap in the disparate use of the Web by postgraduate students and the recognition of the utility of the Web for research evidenced from both a survey of MIS supervisors and a background study of the University's supporting infrastructure, requires that faculty, librarians and the supporting educational institution reassess their roles and adopt more active approaches in supporting a new research environment.

A more interpretive approach in assessing students' citation behaviour is required to properly assess the effect of students' particular circumstances and their utilisation of a Web medium. Ideally a survey assessing students' citer motivations should be juxtaposed with a citation analysis of their research.

While it was the assumption of the current study that MIS students are largely library and information literate, and that they have a greater potential of access to the Internet, there is a need to investigate this group's levels of network literacy as delineated by Savolainen (2002). Applying Savolainen's (2002) cognitive behavioural model may help indicate whether MIS students exhibit the pre-requisite feelings of self-efficacy required to use the Web medium competently and secondly, whether they are being provided with the required incentives to develop an interest to acquire these competencies.

The survey of MIS supervisors' information behaviour was preliminary and focussed on determining a perceived use and support of the WWW for research by this group. This was a small and unique population group, and this may compromise the study's general validity. Findings however should contribute to the user studies' knowledge base, specifically literature investigating the effects of new technologies on information seekers and further, may provide comparative data for related research. A further study on the level of actual use and interventions in supporting the Web for research is required.

\section{References}

Adogbeji, O. B. and Akporhonor, B. A. 2005. The impact of ICT (Internet) on research and studies: the experience of Delta State University students in Abraka, Nigeria. Library Hi Tech News, 10: 17-21.

Aitchison, J. M. H. 21 January 2003. (Aitchison@nu.ac.za). Re: MIS request for information. E-mail to one of the authors. Elizabeth Thompson (ecgthompson@mweb.co.za).

Al-Ansari, H. 2006. Internet use by the faculty members of Kuwait University. The Electronic Library, 24(6): 79 I-803.

American Psychological Association. 2003. Electronic media and URLs. [Online]. http://www.apastyle.org/pubs/elecmedia.html. Accessed 24 June 2006.

Anasi, S. 2006. Internet use pattern of undergraduate students at the University of Lagos, Nigeria. University of Dar es Salaam Library Journal, 8(I\&2): I-I5.

Ani O. E., Esin, J. E. and Edem, E. 2005. Adoption of information and communication technology (ICT) in academic libraries: a strategy for library networking in Nigeria. The Electronic Library, 23(6): $70 \mathrm{I}-708$.

Baeza-Yates, R. and Rebeiro-Neto, B. 2000. Modern information retrieval. Berkeley University Press: California. [Online]. http:// www.aima.berkeley,edu/ hearst/irbook/index.html. Accessed 4 February 2002.

Cosijn, E. 2000. Relevance types in information seeking and use. In: Wormell, I. (ed.) Progress in Library and Information Science in Southern Africa: Proceedings of the First Biennial DISSAnet Conference (ProLISSAI). Pretoria: Center for Information Development, University of Pretoria, pp. 22I-234.

Davis, P. M. 2003. The effect of the Web on undergraduate citation behaviour: guiding student scholarship in a networked age. Portal: Libraries and the Academy, 3(I): 4I-5I.

Davis, P. M. and Cohen, S. A. 200I. The effect of the Web on undergraduate citation behaviour 1996-1999. Journal of the American Society for Information Science and Technology, 52(4):309-314.

Ehikhamenor, F. A. 2003. Internet facilities: use and non-use by Nigerian university scientists. Journal of Information Science, 29(I):35-48.

Fourie, I. 2002. A review of Web information-seeking and searching studies (2000 - 2002): implications for research in the South African context. In Bothma, T and Kaniki, A (eds). Progress in Library and Information Science in Southern Africa: Proceedings of the Second Biennial DISSAnet Conference (ProLISSA2). Pretoria: Infuse, pp. 49-75. 
Friedlander, A. 2002. Dimensions and use of the scholarly information environment. Digital Library Federation and Council on Library and Information Resources, Washington D.C. [Online]. http://www.clir.org/pubs/reports/pub//0/contents.html. Accessed 4 February 2003.

Garfield, E. 1979. Citation indexing: its theory and application in science, technology and humanities. New York, NY: John Wiley.

Geslin, N. 2002. Investigating the acquisition of scholarly resources at University of Natal libraries. Reports prepared for the Project Committee, University of Natal Libraries.

Grimes, D. J. and Boening, C. H. 200I. Worries with the Web: a look at student use of Web resources. College\& Research Libraries, 62(I): II-23.

Halliday, L. 200I. Scholarly communication, scholarly publication and the status of emerging formats. Information Research, 6(4). [Online]. http://www.InformationR.net/ir/paper I I I.html. Accessed 22 June 2007.

Harter, S. P. and Kim, H. J. 1996. Electronic journals and scholarly communication: a citation and reference study. A paper delivered at the Midyear Meeting of the American Society for Information Science, San Diego, CA, May 20-22, 1996. [Online]. ezinfo.ucs.Indiana.edu/ harter/harter-asis96midyear.html. Accessed 7 July 2003.

Herring, S. D. 200I. Faculty acceptance of the World Wide Web for student research. College \& Research Libraries, 62(4): 25I258.

Herring, S. D. 2002. Use of electronic resources in scholarly electronic journals: a citation analysis. College \& Research Libraries, 63 (3):334-340.

Hinchliffe, L. J., Kubiak, C., Hunt, S.K. and Simonds, C.J. 2003. What students really cite: findings from a content analysis of firstyear student bibliographies. Library Orientation Series, 34:36-74.

Hoskins, R. (ed.) 2003. UNP Library Bulletin 35I [Online]. http://www.library.unp.ac.za. Accessed I5 September 2003.

Ingwersen, P. 2000. The cognitive information structures in information retrieval. In: Wormell, I. (ed.) Progress in Library and Information Science in Southern Africa: Proceedings of the First Biennial DISSAnet Conference (ProLISSAI). Pretoria: Centre for Information Development, University of Pretoria, pp. 205-2I7.

Islam, A. and Panda, K.C. 2007. Web-based information retrieval trends of researchers: a case study of Sambalpur University (India). The Electronic Library, 25(6): 757-765.

Jaffe, E. D. 1997. International marketing textbooks: a citation analysis as an indicator of the discipline's boundaries. International Marketing Review, 14(1): 9-19.

Jenkins, P. O. 2002. They're not just using web sites: A citation study of II6 student papers. College and Research Libraries, 63(3): 164.

Jepsen, E. T., Seiden, P., Ingwersen, P., Björneborn, L. and Borlund, P. 2004. Characteristics of scientific Web publications: preliminary data gathering and analysis. Journal of the American Society for Information Science and Technology, 55(14): I2391249.

Kaniki, A. M. 1999. Internet use and training needs of staff of the esAL Consortium, Kwa-Zulu Natal, South Africa: partnerships between historically disadvantaged institutions and historically advantaged institutions (HDIs and HAls). [Online]. http:// www.ifla.org/IV/ifla65/papers/04 I-I I 5e.tm. Accessed 24 June 2003.

Kaniki, A. M. 2000. Prevalent mistakes in the preparation of Library and Information Science (LIS) theses among master's degree candidates at eastern and southern African institutions. In: Wormell, I (ed.) Progress in Library and Information Science in Southern Africa. Proceedings of the first biennial DISSAnet Conference (ProLISSAI). Pretoria: Centre for Information Development, University of Pretoria, pp.39-54.

Kuhn, R. (ed.) 2003. UNP Library Bulletin 355. [Online]. http://www.library.unp.ac.za. Accessed I5 September 2003.

Leckie, G. L. 1996. Desperately seeking citations: uncovering faculty assumptions about undergraduate research process. Journal of Academic Librarianship, 22 (3): $20 \mathrm{I}-208$.

Mgobozi, M. N. and Ocholla, D. N. 2002. A comparison of the use of electronic journals for the dissemination of scholarly information by the University of Natal and University of Zululand. In: Bothma, T and Kaniki, A (eds). Progress in Library and Information Science in Southern Africa. Proceedings of the Second Biennial DISSAnet Conference (ProLISSA2). Pretoria: Infuse, pp.29-47.

Middleton, A. 2005. An attempt to quantify the quality of student bibliographies. Performance Management and Metrics: The International Journal for Library and Information Services, 6(I): 7-18.

Mugwisi, T. and Ocholla, D. N. 2002. Internet use, trends and attitudes among academic librarians: a comparative study between the University of Zimbabwe and the University of Zululand. In: Bothma, T and Kaniki, A (eds). Progress in Library and Information Science in Southern Africa. Proceedings of the Second Biennial DISSAnet Conference (ProLISSA2). Pretoria: Infuse, pp. $143-165$.

Naidoo, K. (NaidooKris@nu.ac.za). 2003 May 16. Re: ITD user stats. E-mail to one of the authors. Elizabeth Thompson (ecgthompson@mweb.co.za).

Nel, J. G. 200I. The information seeking process: is there a six sense. Mousaion 19(2):23-32.

Ngai, E.W. T., Law, C. C. H., Chan, S. C. H. and Wat, F. K. T. 2008. Importance of the internet to human resource practitioners in Hong Kong. Personnel Review, 37(I): 66-84.

Ngulube, P. 2005. Improving the quality of research outputs in higher education through knowledge sharing and collaboration: A case study. Mousaion, 23(1): 39-6I.

Ocholla, D. N. 1999. Insights into information seeking and communicating behaviour of academics. International Information and Library Review, $31:$ I 19-143.

Odlyzko, A. 200I. The rapid evolution of scholarly communication. [Online]. http://www.research.att.com/ amo. Accessed 2 October 2003.

Odero-Musakali, D. and Mutula, S. M. 2007. Internet adoption and assimilation in Kenyan university libraries. Library Review 56(6): 464-475.

SA Jnl Libs \& Info Sci 2008, 74(2) 
Olalude, F. 2007. Utilisation of Internet sources for research by information professionals in Sub-Saharan Africa. African Journal of Library, Archives and Information Science, I7(I): 53-58.

Ojedokun, A. A. 200I. Internet access and usage by students of the University of Botswana. African Journal of Libraries, Archives and Information Science, II(2): 97-I07.

Oppenheim, C. and Smith, R. 200I. Student citation practices in an Information Science Department. Education for Information, 19: 299-323.

Omotayo, B. O. 2006. A survey of Internet access and usage among undergraduates in an African university. The International Information and Library Review 38: 215-224.

Rosenberg, D. 200I. The sustainability of libraries and resource centres in Africa. In: Stilwell, C., Leach, A and Burton, S. (eds). Knowledge, information and development: an African perspective. Pietermaritzburg: School of Human and Social Studies, University of Natal, pp. II-23.

Rowley, J. 2002. JISC user behaviour monitoring and evaluation framework: framework report 2002, cycles I-3. [Online]. http:/ /www.jisc.ac.uk/uploaded_documents/cycle\%201-3\%20report. Accessed 10 August 2006.

Sam, J. and Tackie, S. N. B. 2007. Citation analysis of dissertations accepted by the Department of Information Studies, University of Ghana, Legon. African Journal of Library and Information Science, I7(2): I I 7- I 24.

Savolainen, R. 2002. Network competence and information seeking on the Internet: from definitions towards a social cognitive model. Journal of Documentation, 58(2):21।-226.

Schwartz, J. 2002. Internet access and end-user needs: computer use in an academic library. Reference and User Services Quarterly, $4 \mathrm{I}$ (3): 253-263.

Shezi, M. S. 2006. An investigation into the use of the internet by students at St. Joseph's Theological Institute, KwaZulu-Natal, South Africa. M.I.S. thesis. Pietermaritzburg: University of KwaZulu-Natal.

Smith, L.C. 198I. Citation analysis. Library Trends, 30 (2):83-106.

Spennemann, D. H. R. 2007. Learning and teaching 24/7: daily internet usage patterns at nine Australian universities. CampusWide Information Systems, 24(I): 27-44.

Sturges, P. and Neill, R. 1998. The quiet struggle: information and libraries for the people of Africa. 2nd ed. London: Mansell.

Tenopir, C. and Ennis, L. 2002. A decade of digital reference: I99I-200I. Reference and User Services Quarterly, 4I(3): $264-274$.

Thelwall, M. 2002. Research dissemination and invocation on the Web. Online Information Review, 26(6):4I3-420.

Thompson J. E. and Cronje, J. 200 I. A dynamic model of information literacy acquisition. Mousaion, 19(2):3-14.

Parker, A. 2007. Link rot: how the inaccessibility of electronic citations affects the quality of New Zealand scholarly literature. The New Zealand Library and Information Management Journal, 50(2): I72-192.

University of Natal. 2003. About NU: libraries and IT resources: information technology. [Online]. http://www.nu.ac.za. Accessed 20 September 2002.

University of Natal Library, Pietermaritzburg. 2000. Librarians' $38^{\text {th }}$ annual report, 2000. University of Natal: Pietermaritzburg.

Urquhart, C. 2003. Trends in the use of electronic journals in higher education in the UK: views of academic staff and students. D-Lib Magazine, 9(6). [Online]. http://webdoc.gwdg.de/edoc/aw/d-lib/dlib/june03/urquhart/06urquhart.html. Accessed I0 August 2003.

Wachbroit, R. 200I. Reliance and reliability: the problem of information on the Internet. iMP Magazine. [Online]. http:// www.cisp.org/imp/may 2001/05 0/wachbroit.htm. Accessed 8 May 2003.

Williams, V. K. and Fletcher, C. L. 2006. Materials used by master's students in engineering and the implications for collection development: a citation analysis. Issues in Science and Technology Librarianship, 45. [Online]. http://www.istl.org/06-winter/ refereed I.html. Accessed 4 February 2008.

Zhang, L. 2007. Discovering information use in agricultural economics: a citation analysis study. The Journal of Academic Librarianship, 33(3):403-4I3.

Zhang, Y. 1998. The impact of Internet-based electronic resources on formal scholarly communication in the area of library and information science: a citation analysis. Journal of Information Science, 24(4):24I-254. 